\title{
国国pubvet
}

https://doi.org/10.31533/pubvet.v14n6a599.1-4

\section{Citorredução com quimioterapia neoadjuvante em mastocitoma canino: Relato de dois casos}

\author{
Letícia Roskosz Gonzalez ${ }^{1}$ \\ ${ }^{I}$ Graduanda em Medicina Veterinária pela Universidade Anhembi Morumbi. São Paulo - SP Brasil. E-mail: letigonzalez30@outlook.com
}

\begin{abstract}
Resumo. Objetivou-se com esse trabalho relatar a utilização de quimioterapia neoadjuvante para citorredução pré-operatória de mastocitoma em dois cães. $\mathrm{O}$ mastocitoma é um dos tumores cutâneos mais comuns na clínica de pequenos animais. Caracteriza-se por ser uma neoplasia maligna originada dos mastócitos. Acomete frequentemente as regiões perineal, genital e inguinal, também podendo atingir tronco, membros, cabeça e pescoço. Cães de meia idade a idosos e raças braquicefálicas parecem ser os mais predispostos. Esta neoplasia tem um comportamento variado, podendo se apresentar como formações circunscritas, alopecias, eritematosas e edemaciadas, de consciência macia ou não, ulcerada ou não, manifestando desde um único nódulo até múltiplos nódulos. O diagnóstico é baseado nos achados de citologia aspirativa, entretanto o exame histopatológico é capaz de graduar o grau de malignidade em grau I, II ou II ou em alto e baixo grau. O tratamento indicado é a abordagem cirúrgica, acompanhada ou não de quimioterapia ou radioterapia. A utilização da quimioterapia como método neoadjuvante à cirurgia tem como propósito reduzir o tumor e ampliar a margem cirúrgica de segurança.
\end{abstract}

Palavras chave: canino, cirurgia, mastocitoma, neoplasia, quimioterapia

\section{Cytoreduction with neoadjuvant chemotherapy in canine mastocytoma: report of two cases}

\begin{abstract}
The objective of this work is related to the use of neoadjuvant chemotherapy for preoperative mastocytoma cytoreduction in two dogs. Mastocytoma is one of the most common skin tumors in small animal clinics. It is characterized by being a malignant neoplasm originating from mast cells. It often accompanies as perineal, genital and inguinal regions, and can also reach trunk, limbs, head and neck. Older middle-aged dogs and brachycephalic breeds seem to be the most predisposed. This neoplasia has a varied behavior, may present as circumscribed, allopathic, erythematous and swollen formations, with or without soft conscience, ulcerated or not, manifesting from a single nodule to multiples nodules. The diagnosis is based on the findings of aspiration cytology, however histopathological examination can detect the degree of malignancy in grade I, II or II or in high and low grade. The indicated treatment is a surgical approach, whether or not accompanied by chemotherapy or radiotherapy. The use of chemotherapy as a neoadjuvant method in surgery has the effect of reducing the tumor and increasing the surgical safety margin.
\end{abstract}

Keywords: canine, surgery, mastocytoma, neoplasy, chemotherapy

\section{Introdução}

A prevalência de câncer em cães está aumentando consideravelmente. A crescente incidência das afecções neoplásicas nessa espécie tem várias razões, entre elas está a maior longevidade observada nestes animais (Bariani et al., 2007; Melo et al., 2013). 
O mastocitoma caracteriza-se por transformações neoplásicas e proliferação anormal de mastócitos, podendo ser de origem cutânea ou visceral (Palma et al., 2009). Mastocitoma cutâneo é o mais comum do cão, compreende 7 a $21 \%$ dos tumores cutâneos caninos e 11 a $27 \%$ das neoplasias malignas (Furlani et al., 2008). O mastocitoma ocorre principalmente em cães com idade média de 8 a 9 anos, e não existe aparente predileção por sexo. As raças mais predispostas são Boxer, Boston Terrier, Bull Terrier, Labrador Retriever, Fox Terrier, Beagle e Schnauzer (Bariani et al., 2007).

A apresentação clínica do mastocitoma cutâneo é bastante variável, sendo encontradas desde lesões pequenas, solitárias, de crescimento lento até formações ulceradas, de crescimento e disseminação rápida (Melo et al., 2013; Rodrigues \& Calazans, 2015). A lesão tumoral pode estar associada com prurido, edema e eritema (Prado et al., 2012). 50\% dos mastocitomas cutâneos localizam-se no tronco e nas regiões perineal, genital e inguinal, $40 \%$ nos membros e $10 \%$ na cabeça e no pescoço (Furlani et al., 2008).

A citologia aspirativa com agulha fina trata-se de um método seguro que permite o diagnóstico do mastocitoma canino. No entanto, a histopatologia faz-se imperativa para a determinação do grau histológico da neoplasia e, consequentemente, para o delineamento adequado do tratamento, possibilitando o aumento da sobrevida (Furlani et al., 2008). A palpação abdominal e os exames radiográficos e ultrassonográficos devem ser realizados para detectar linfadenomegalia, hepatomegalia e esplenomegalia. Os exames laboratoriais devem ser incluídos, rotineiramente, na avaliação de qualquer animal com suspeita de neoplasia (Palma et al., 2009).

O tratamento mais comumente utilizado em mastocitomas cutâneos caninos envolve a ressecção cirúrgica seguida de quimioterapia antineoplásica. Apesar de a cirurgia ser o tratamento de eleição, em alguns casos devido à localização e o tamanho do tumor é necessária a utilização de quimioterapia neoadjuvante na tentativa de reduzir o tamanho da lesão facilitando a ressecção com margens adequadas de segurança (Jark et al., 2013). Os fármacos mais utilizados na quimioterapia do mastocitoma canino incluem a vinblastina, lomustina e a prednisolona (Rodrigues \& Calazans, 2015).

\section{Relatos de casos}

\section{Caso clínico 1}

Um cão da raça poodle, fêmea, com 14 anos, peso de $6 \mathrm{~kg}$, foi atendido no Hospital Veterinário Anhembi Morumbi no dia 02 de setembro de 2019, com histórico de um nódulo cutâneo circunscrito, eritematoso, alopécico e de consistência firme, localizado em membro torácico direito, na região dos dígitos. Animal apresentava prurido frequente no local. Tinha evolução de um mês e media aproximadamente $3 \times 3 \times 2,5 \mathrm{~cm}$. Tutor relatou normorexia, normodipsia, normoquezia, negava êmese, diarreia, tosse, alterações respiratórias e neurológicas. No exame clínico o animal apresentava-se hidratado, mucosas normocoradas, tempo de perfusão capilar (TPC) de dois segundos, frequência cardíaca de $116 \mathrm{bpm}$, e temperatura retal de $38,2^{\circ} \mathrm{C}$. Na palpação foi constatado que o animal também apresentava linfadenomegalia significativa em linfonodo pré-escapular direito.

Em colega, foi realizado exame citopatológico da formação e o resultado foi sugestivo de mastocitoma. Para realizar o estadiamento da neoplasia foi realizado exame ultrassonográfico de abdômen e radiografia torácica e em ambos não foi observado sinais de presença de metástase à distância.

No dia 9 de setembro de 2019 foi realizada a quimioterapia neoadjuvante com o objetivo da citorredução das dimensões do nódulo nos dígitos para possibilitar maior margem cirúrgica e preservação da pata do animal. O paciente foi submetido a duas sessões semanais de quimioterapia com vimblastina na dosagem de $2 \mathrm{mg} / \mathrm{m}^{2}$ por via intravenosa, associado com prednisona na dose inicial de 2 $\mathrm{mg} / \mathrm{kg}$, uma vez ao dia, por via oral. Após a segunda sessão de quimioterapia neoadjuvante, o paciente apresentou redução significativa do tamanho do tumor e do linfonodo e foi então encaminhado para a realização da amputação do quarto dígito do membro torácico direito. A massa tumoral foi enviada para exame histopatológico e confirmou a presença de mastocitoma grau II/mastocitoma de alto grau.

Passados quinze dias do procedimento cirúrgico, o animal retornou com bom estado geral, mas apresentava aumento de volume em linfonodo pré-escapular direito. Foi realizada a primeira quimioterapia pós-cirurgia mantendo o mesmo protocolo de vimblastina e prednisona. Após sete dias tutor relatou que animal passou a semana apático e na inspeção foi constatada linfadenomegalia de linfonodo submandibular 
direito e ausência de regressão do tamanho do linfonodo pré-escapular direito. Frente esses resultados, optouse pela continuação do tratamento utilizando apenas o medicamento Palladia ${ }^{\circledR}$.

\section{Caso clínico 2}

Um cão sem raça definida, fêmea, com 15 anos, peso de $10 \mathrm{~kg}$, foi atendido no Hospital Veterinário Anhembi Morumbi no dia 30 de setembro de 2019, com histórico de mastocitoma em membro pélvico, diagnosticado por exame citopatológico realizado em colega. A formação tinha uma evolução de sete meses, era circunscrita, alopécica, arroxeada e ulcerada, de consistência macia e aderida a região medial do membro pélvico direito, com dimensões aproximadas de $13 \times 10 \times 7,5 \mathrm{~cm}$. O tutor relatou anorexia nos últimos dias e alguns episódios de êmese. Relata normodipsia, normoquezia e urina normal e negava diarreia, tosse, alterações respiratórias e neurológicas. No exame clínico o animal apresentava desidratação leve, mucosas hipocoradas, tempo de perfusão capilar (TPC) de dois segundos, frequência cardíaca de $164 \mathrm{bpm}$, frequência respiratória de $44 \mathrm{mrpm}$ e temperatura retal de $38,3{ }^{\circ} \mathrm{C}$. Não foi constatada nenhuma alteração durante a palpação e os linfonodos não estavam reativos.

No mesmo dia foi instituído o tratamento com vimblastina na dose de $2 \mathrm{mg} / \mathrm{m}^{2}$ por via intravenosa, associado com prednisona na dose inicial de $2 \mathrm{mg} / \mathrm{kg}$, uma vez ao dia, por via oral. Foi eleito esse protocolo inicial com o objetivo de citorreduzir a massa tumoral do membro pélvico direito, que se apresentava grande o suficiente para ter atrito com o chão e acarretar em ulcerações. Uma semana após a primeira dose do quimioterápico observou diminuição da neoformação e melhora no apetite do animal. Após a segunda sessão de quimioterapia não houve redução da formação, que se apresentava mais arroxeada, e o animal manifestava um emagrecimento progressivo. $\mathrm{O}$ paciente foi então submetido à biópsia excisional com anaplastia, seguido da remoção do linfonodo inguinal direito. Foi então confirmada a presença de mastocitoma subcutâneo infiltrativo moderadamente diferenciado e linfonodo extensamente comprometido.

Após três dias do procedimento cirúrgico, o animal retornou com bom estado geral, prurido intenso na ferida cirúrgica e apresentando uma nova formação nodular na região perineal do lado direito, de consistência macia, não alopecica e não ulcerada, sugestivo de ser um outro nódulo de mastocitoma. Dez dias após a remoção da neoformação foi realizada a primeira sessão de quimioterapia pós-cirurgia com vimblastina na dose de $2 \mathrm{mg} / \mathrm{m}^{2}$ por via intravenosa, associado com prednisona na dose inicial de $1 \mathrm{mg} / \mathrm{kg}$, uma vez ao dia, por via oral. Após essa sessão de quimioterapia, o tutor decidiu abandonar o tratamento.

\section{Discussão do caso}

As raças braquicefálicas são as mais predispostas em apresentar mastocitomas (Palma et al., 2009). Apesar dos cães relatados não pertencerem ao grupo racial mais incidente, apresentavam uma idade de risco, já que esse tipo de tumor é frequente em animais mais velhos (Macedo, 2014).

Nos casos relatados o tumor estava localizado em membros e segundo Furlani et al. (2008), o mastoctioma se apresenta mais frequentemente em região de tronco, região perineal e genital, mas corriqueiramente acomete membros. Segundo Ríos (2008), o tumor de mastócitos pode aparecer como massas dermoepidérmicas, podendo ser macio, flutuante ou firme, discreto ou difuso, pequeno ou grande e se apresentando como qualquer tipo de lesão cutânea primária ou secundária, incluindo máculas, pápulas ou nódulos, sendo na maioria das vezes formações únicas. Em ambos os casos clínicos descritos as formações eram nódulos cutâneos únicos, firmes, circunscritos, eritematosos e alopécicos.

Para o diagnóstico foi utilizado o exame citopatológico, o que entra de acordo com o que foi citado por Rodrigues (2015), em que a avaliação citológica com colheita de material por punção aspirativa com agulha fina (PAAF) é o meio mais expedito para diagnosticar a presença de um mastocitoma cutâneo, tornando possível a discussão das futuras condutas terapêuticas. Para o estabelecimento do grau do mastocitoma e consequentemente a determinação do tratamento que será instituído e do prognóstico da doença é necessário o exame histopatológico, como descrito por Blackwood et al., citado por Lopes (2014).

A excisão cirúrgica é indicada para todos os mastocitomas e devem ter margens de segurança de no mínimo $2 \mathrm{~cm}$, como descrito por Pereira et al. (2018). Contudo, nos casos relatados, não era possível realizar uma cirurgia com ampla margem de segurança, portanto optou-se inicialmente pela quimioterapia como método neoadjuvante com o objetivo de conseguir a citorredução e assim melhorar 
a abordagem cirúrgica. De acordo com Rodrigues (2015) a abordagem quimioterápica neoadjuvante possibilita a diminuição do volume total da massa tumoral até $81 \%$, contribuindo para a ressecção cirúrgica de mastocitomas de grandes dimensões ou localizados em regiões anatômicas que não permitem uma extirpação completa.

\section{Conclusão}

Há uma alta frequência de mastocitoma na clínica médica de pequenos animais e o tratamento principal é a excisão cirúrgica. A quimioterapia neoadjuvante à cirurgia com intenção de citorredução pode ser adotada em alguns casos, sendo de grande vantagem por propiciar melhor abordagem cirúrgica e uma maior margem de segurança.

\section{Referências bibliográficas}

Bariani, M. H., Souza, F. B., Talon, D. B., \& Santos, P. C. G. dos. (2007). Mastocitoma cutâneo em cães. Revista Científica Eletrônica de Medicina Veterinária, 4.

Furlani, J. M., Daleck, C. R., Vicenti, F. A. M., De Nardi, A. B., Pereira, G. T., Santana, Á. E., Eurides, D., \& da Silva, L. A. F. (2008). Mastocitoma canino: estudo retrospectivo. Ciência Animal Brasileira, 9(1), 242-250. DOI: https://www.doi.org/index.html

Jark, P. C., Raposo, T. M. M., Alves, C. E. F., Macente, B. I., Gutierrez, R. R., Nardi, A. B. de, Amorim, R. L., \& Costa, M. T. (2013). Quimioterapia neoadjuvante com vimblastina e lomustina no tratamento de um caso de mastocitoma cutâneo canino com múltiplos fatores prognósticos negativos e sobrevida superior a dois anos. Revista Portuguesa de Ciências Veterinárias, 108, 147-150.

Lopes, Y. M. (2014). Modalidades terapêuticas empregadas no tratamento do mastocitoma cutâneo canino. Trabalho técnico-científico de conclusão de curso (graduação em medicina veterinária) Faculdade de Medicina Veterinária, Universidade Federal do Rio Grande do Sul. Porto Alegre.

Macedo, T. R. (2014). Comparação da eficácia do mesilato de imatinibe com a vimblastina associada a prenisona no tratamento do mastocitoma canino: estudo clínico, histopatológico, imunohistoquímico e molecular. 2014. 149 f. Tese (Doutorado em Ciências) - Faculdade de Medicina Veterinária e Zootecnia, Universidade de São Paulo, São Paulo. DOI: 10.11606/T.10.2014.tde-05012015-094225

Melo, I. H. S., Magalhães, G. M., Alves, C. E. F., \& Calazans, S. G. (2013). Mastocitoma cutâneo em cães: uma breve revisão. Revista de Educação Continuada Em Medicina Veterinária e Zootecnia, 11(1), 38-43. DOI: https://doi.org/10.36440/recmvZ.v11i1.5373

Palma, H. E., Martins, D. B., Basso, P. C., Amaral, A. S. do, Teixeira, L. V., \& Lopes, S. T. dos A. (2009). Mastocitoma cutâneo canino: revisão. Medvep - Revista Científica de Medicina Veterinária - Pequenos Animais e Animais de Estimação, 7, 523-528.

Pereira, L. B. de S. B., Pessoa, H. F., Fonseca Filho, L. B., Medeiros, N. C. A., Pontes, M. B., Lima, J. D. O., Wanderley, G. M. M., \& Nascimento, J. C. S. (2018). Mastocitoma de alto grau em um cão: relato de caso. PUBVET, 12(9), 1-5. DOI: https://doi.org/10.31533/pubvet.v12n9a166.1-5

Prado, A. A. F., Leão, D. A., Ferreira, A. O., Machado, C., \& Maria, D. A. (2012). Mastocitoma em cães: Aspectos clínicos, histopatológicos e tratamento. Enciclopédia Biosfera, Centro Científico Conhecer, 8(14), 2151.

Ríos, A. (2008). Mastocitoma canino y felino. Clínica Veterinaria de Pequeños Animales, 28(2), 135-142.

Rodrigues, P. C., \& Calazans, S. G. (2015). Mastocitoma cutâneo disseminado em cão - Relato de caso. Investigação, 14(3). DOI: https://doi.org/10.26843/investigacao.v14i3.962

Rodrigues, A. R. S. R. (2015). Quimioterapia e terapia molecular no tratamento de mastocitomas caninos: revisão sistemática. Dissertação (Mestrado em medicina veterinária) - Faculdade de Medicina Veterinária, Universidade Lusófona de Humanidades e Tecnologias. Lisboa, p. 40.

Recebido: 19 de fevereiro, 2020

Aprovado: 25 de maio, 2020

Disponível online: 14 julho, 2020.

Licenciamento: Este artigo é publicado na modalidade Acesso Aberto sob a licença Creative Commons Atribuição 4.0 (CC-BY 4.0), a qual permite uso irrestrito, distribuição, reprodução em qualquer meio, desde que o autor e a fonte sejam devidamente creditados 